\title{
Adjusting the compass: new insights into the role of angiogenesis in Alzheimer's disease
}

\author{
Wilfred A Jefferies ${ }^{1,2,3,4,5,6^{*}}$, Katherine A Price ${ }^{7,8}$, Kaan E Biron ${ }^{1,2,3}$, Franz Fenninger ${ }^{1,2}$, Cheryl G Pfeifer ${ }^{1,3}$ \\ and Dara L Dickstein ${ }^{7,8}$
}

\begin{abstract}
Growing evidence suggests that vascular perturbation plays a critical role in the pathogenesis of Alzheimer's disease (AD). It appears to be a common feature in addition to the classic pathological hallmarks of amyloid beta (Aß) plaques and neurofibrillary. Moreover, the accumulation of $A \beta$ in the cerebral vasculature is closely associated with cognitive decline, and disruption of the blood-brain barrier (BBB) has been shown to coincide with the onset of cognitive impairment. Although it was originally hypothesized that the accumulation of $A \beta$ and the subsequent disruption of the BBB were due to the impaired clearance of $A \beta$ from the brain, a body of data now suggests an alternative hypothesis for vascular dysfunction in $\mathrm{AD}$ that amyloidogenesis promotes extensive neoangiogenesis leading to increased vascular permeability and subsequent hypervascularization. In this review, we discuss the role $A \beta$ plays in angiogenesis of the neurovasculature and BBB and how it may contribute to the pathogenesis of AD. These studies suggest that interventions that directly or indirectly affect angiogenesis could have beneficial effects on amyloid and other pathways in AD.
\end{abstract}

Introduction: Alzheimer's disease, the blood-brain barrier, and angiogenesis

For decades, the possible causes of Alzheimer's disease (AD) have been debated, yet the true cause of this agerelated neurological disorder remains unclear. Since the hallmark pathologies of $\mathrm{AD}$ are the amyloid beta $(\mathrm{A} \beta)$ plaques, the dominant hypothesis regarding $\mathrm{AD}$ (the amyloid cascade hypothesis') is that this 39 - to 43 -amino acid $A \beta$ peptide is the neurotoxic cause of brain dysfunction and that its increased accumulation in the brain parenchyma leads ultimately to the memory loss and cognitive decline that are clinically characteristic of the disease [1]. However, efforts in developing effective AD therapeutics based on this hypothesis have so far proven unsuccessful. The reasons for this are complex, and clinical trial measures such as achieving effective drug levels, targeting an appropriate phase of the disease, adequate 'end-point' measures, and toxicity should all be considered. The failure of clinical trials based on the amyloid cascade hypothesis has also prompted a reassessment of $\mathrm{AD}$ pathogenesis.

\footnotetext{
* Correspondence: wilf@msl.ubc.ca

${ }^{1}$ Michael Smith Laboratories, The University of British Columbia, 301-2185

East Mall, Vancouver, BC V6T 1Z4, Canada

${ }^{2}$ Department of Microbiology and Immunology, University of British

Columbia, 1365-2350 Health Sciences Mall, Vancouver, BC V6T 1Z3, Canada

Full list of author information is available at the end of the article
}

Although $A \beta$ is still clearly implicated in $A D$, the field has been prompted to consider alternative hypotheses beyond $A \beta$ as the central nexus of $A D$. The disease pathogenesis of $\mathrm{AD}$ is undoubtedly complex and multi-factorial. There is mounting evidence that changes in the cerebral and peripheral vasculature can lead to altered blood flow to the brain, and is a risk factor for developing $\mathrm{AD}[2,3]$. This alternative theory of $\mathrm{AD}$ pathogenesis has arisen through a variety of experimental $A D$ studies in which blood-brain barrier (BBB) dysfunction and impaired cerebral blood flow (CBF) have been observed [4-9] and reviewed in $[10,11]$, suggesting that compromised clearance mechanisms at the $\mathrm{BBB}$ contribute to the accumulation of $\mathrm{A} \beta$ in the AD brain. New research also indicates that pathological cerebral angiogenesis may occur as a result of $A \beta$ accumulation and result in BBB dysfunction in AD. Here, we review the current body of evidence regarding the vascular origins of $\mathrm{AD}$ and assess the conflicting reports regarding the role of cerebral angiogenesis in $\mathrm{AD}$ etiology.

\section{Mechanisms of Alzheimer's disease pathogenesis: the amyloid cascade hypothesis versus the vascular hypothesis}

Alzheimer's disease is the most common age-related neurological disorder of the first world. Biochemically, it is 
characterized by $A \beta$ plaque formation, intraneuronal tau hyperphosphorylation, and neuronal loss [12,13]. Elevated cytokine expression and microglial activation have also been observed and are contributors to the neuroinflammatory changes observed in post-mortem brains [14]. Clinically, the disease is characterized by worsening memory impairment, decline in cognitive ability, and eventual death [15]. Effective therapies for $\mathrm{AD}$ have so far eluded researchers and clinicians; however, the huge social and economic cost of caring for patients with AD means it is necessary to continue to research its causes in the hopes that effective therapies may be found.

For the last two decades, the dominant hypothesis regarding the cause of sporadic, non-familial AD has been the 'amyloid cascade hypothesis', which suggests that increased aberrant accumulation of the $A \beta$ peptide in the brain leads to formation of plaque deposits, ultimately causing neuronal dysfunction and death. The $A \beta$ peptide is generated from the cleavage of the amyloid precursor protein (APP), a normally expressed transmembrane protein (for extensive review, see [16]). Cleavage of APP by $\beta$-site cleaving enzyme and $\gamma$-secretase generates $A \beta$, whereas processing of APP by $\alpha$-secretase precludes A $\beta$ formation by cleaving the protein within the $A \beta$ domain. The accumulation of the $A \beta$ peptide in the brain is central to the amyloid cascade hypothesis, despite the fact that $A \beta$ can be extensively present in the human brain in the absence of AD symptoms [17-20].

Despite this paradox, much attention has been focused on determining the mechanisms that lead to the accumulation of $A \beta$ in $A D$. Research increasingly points to impaired clearance of brain $A \beta$ as a more relevant factor in $\mathrm{AD}$ pathogenesis. A critical step in understanding the cause of $\mathrm{AD}$ is identifying what the initiating steps are in the neurodegenerative cascade. Two key vascular precursors to the neurodegenerative changes and $A \beta$ deposition occurring in AD are the breakdown of the BBB [21,22] and impaired CBF (hypoperfusion) [23]. In addition, the inflammatory changes observed in $\mathrm{AD}$ brains can lead to the upregulation of angiogenic mediators such as vascular endothelial growth factor (VEGF), causing pathological angiogenesis through which $A \beta$ may further be generated [24]. The influence of these factors will be discussed in greater detail below, and collectively they provide a strong case that $\mathrm{AD}$ is a disease of vascular origin.

\section{The blood-brain barrier in Alzheimer's disease: vascular dysfunction}

$\mathrm{CBF}$ in the brain is a key factor impacting $\mathrm{BBB}$ permeability and brain $A \beta$ concentration. Although $C B F$ decay is associated with normal aging, more severe $\mathrm{CBF}$ reductions have been detected in older individuals at a high risk of developing $\mathrm{AD}$ prior to the onset of $\mathrm{A} \beta$ accumulation and cognitive decline [4-8]. Recent studies into CBF in humans carrying the apolipoprotein $\mathrm{E}$ (ApoE) $\varepsilon 4$ allele (the major genetic risk factor for late-onset $\mathrm{AD}$ ) showed that these individuals had a larger regional proportion of deteriorated CBF compared with individuals not carrying the allele [25-28]. Several studies of $\mathrm{AD}$ pathogenesis in rats and mice have also described impaired CBF (reviewed extensively by Zlokovic [23]).

A compromised $\mathrm{BBB}$ in $\mathrm{AD}$ can result in the accumulation of unwanted and potentially neurotoxic molecules in the brain. The BBB is defined as the 'microvasculature' of the brain and is formed by a continuous layer of capillary endothelium joined by tight junctions that are generally impermeable (except by active transport) to most large molecules, including antibodies and other proteins (Figure 1) [29]. The unique properties of the BBB preclude

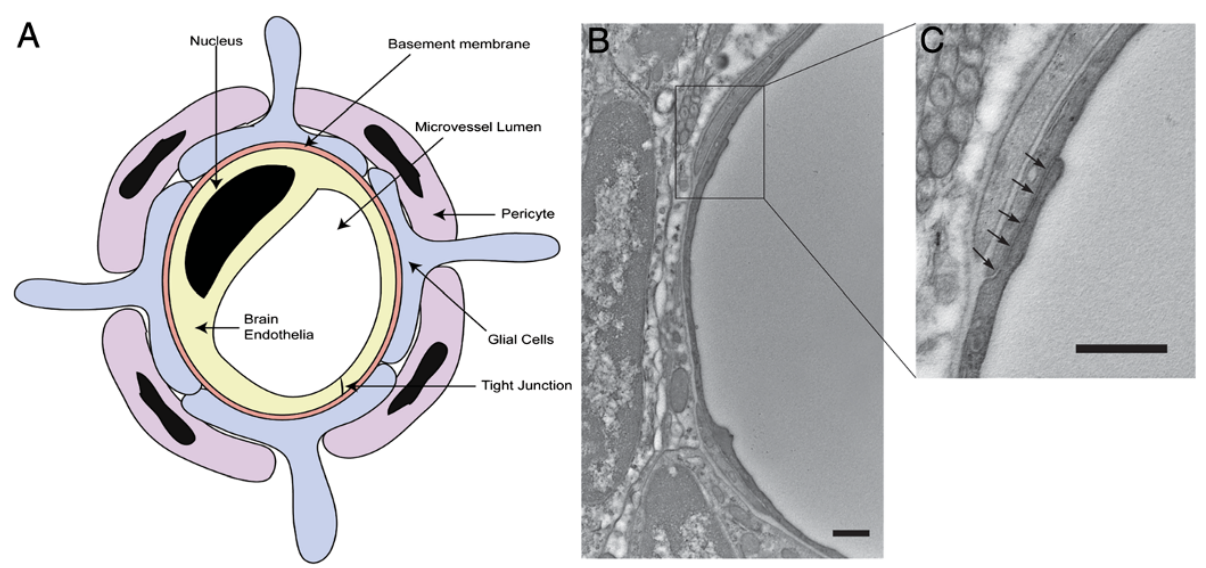

Figure 1 Schematic diagram of the structure of the blood-brain barrier (BBB). The BBB is created by the tight apposition of endothelial cells lining blood vessels in the brain, forming a barrier between the circulation and the brain parenchyma. (A) A thin basement membrane, composed of laminin, fibronectin, and other proteins, surrounds the endothelial cells, associated astrocytes, and pericytes, providing both mechanical support and a barrier function. (B, C) Electron micrograph of an endothelial type II tight junction (simple overlap; black arrows). Magnification is $9,000 \times$ (B) with a magnified inset of $60,000 \times$ (C). Scale bars are $500 \mathrm{~nm}$ respective to the magnification. 
the free exchange of solutes between the brain and blood, thereby protecting the brain from indiscriminate exposure to macromolecules, peptides, and other potentially toxic molecules that may enter via the peripheral circulation [29]. Physical breakdown of the BBB may result from disruption of tight junctions, adherens junctions, pericyte reduction, and degradation of the capillary basement membrane [23,30]. Age-dependent loss of pericytes can lead to reduced expression of tight junction adaptor proteins such as occludin and ZO-1 and to an increase in bulk flow across the BBB [30].

We have previously examined the permeability of the BBB in the Tg2576 mouse model of AD. Using the quantitative Evans blue analysis, we demonstrated that the BBB is compromised in Tg2576 mice compared with non-transgenic controls [21]. Critically, BBB disruption was present in young (4-month-old) $\mathrm{Tg} 2576$ mice before any signs of $\mathrm{AD}$ were apparent, indicating that early $\mathrm{BBB}$ disruption may facilitate the accumulation of $A \beta$ in the brain before other symptoms are apparent [21]. Zlokovic [29] has similarly described an age-dependent decline in $\mathrm{BBB}$ ability to clear $\mathrm{A} \beta$ in animal brains. These findings were also supported by a later study by our laboratory which showed $\mathrm{BBB}$ permeability and subsequent restoration of BBB integrity with $A \beta$ immunization in $\operatorname{Tg} 2576$ mice compared with non-transgenic controls in 12- and 15-month-old mice [22].

Additional proteins at the $\mathrm{BBB}$ which act to regulate brain $A \beta$ levels may be disrupted in $\mathrm{AD}$. The receptor for advanced glycation products (RAGE) is a multi-ligand receptor that regulates the entry of peripheral $A \beta$ to the brain and is also implicated in BBB breakdown and AD pathogenesis. It binds soluble $A \beta$ in the nanomolar range, and its expression is upregulated by the variety of ligands it binds, including $\mathrm{A} \beta$ and pro-inflammatory cytokine-like mediators [31-34]. Because of this, increases in $A \beta$ levels lead to the upregulation of RAGE, further facilitating the entry of $A \beta$ into the cerebral neurons, microglia, and vasculature [34]. Beyond facilitating the entry of $A \beta$ into the brain, in vitro studies have implicated RAGE in the vascular pathogenesis of $\mathrm{AD}$ by mediating apoptosis in the brain and suppression of CBF [31,34].

In addition to RAGE, low-density lipoprotein receptorrelated protein 1 (LRP1) is the main receptor clearing $A \beta$ from the abluminal side of the BBB [35]. It is a member of the low-density lipoprotein receptor family and has been linked to AD both biochemically and genetically [36,37] and may be involved in APP processing [35]. Deane and Zlokovic [35] used surface plasmon resonance analysis to show that LRP1 has a high affinity for A $\beta 1-40$ and less affinity for $\beta$-sheet A $\beta 1-42$. Interestingly, LRP1 is downregulated with age and in $\mathrm{AD}$, and, although the mechanisms behind this downregulation remain unclear [35], research in mouse brains demonstrates that the presence of the
ApoE $4 \varepsilon$ allele blocks LRP1-mediated clearance of $A \beta$ from the brain parenchyma [38]. Although there are many additional factors that ultimately impact $A \beta$ concentration in the brain, including the rate of $A \beta$ production and oligomerization [39-41], a disruption to these critical BBB proteins will have a significant influence in determining brain $\mathrm{A} \beta$ concentration and, in turn, its pathological consequences [42].

\section{Pathological angiogenesis in Alzheimer's disease}

The case for a vascular etiology of $\mathrm{AD}$ is strengthened by the close association of $\mathrm{AD}$ with cerebrovascular amyloid angiopathy (CAA), which is present in approximately $90 \%$ of $\mathrm{AD}$ cases and $50 \%$ of the population over 90 [43]. CAA is characterized by the presence of $A \beta$ in the pial and intracerebral small arteries and capillaries $[44,45]$ and is associated with microaneurysms and dementia [46]. Recently, angiogenesis has been proposed as a possible mediator of $\mathrm{A} \beta$ accumulation in $\mathrm{AD}$, although there are conflicting reports regarding whether angiogenesis is a direct or indirect initiator of $\mathrm{BBB}$ disruption in response to direct activation by $A \beta$ or by other mechanisms such as oxidative stress, inflammation, and hypoxia.

Research supporting a role for pathological angiogenesis in $\mathrm{AD}$ suggests that it occurs as a compensatory response to impaired CBF [47], which has been found in AD mouse models [48-50] and post-mortem studies [51]. The release of angiogenic cytokines such as thrombin and VEGF via stimulation of inflammatory pathways in $\mathrm{AD}$ also contributes to angiogenesis [24]. Vagnucci and Li [47] hypothesized a cycle of neurotoxicity and death initiated by the release of thrombin following $A \beta$-induced neuroinflammatory responses. The release of thrombin causes cerebral endothelial cells to secrete $A \beta$, promoting generation of reactive oxygen species and further endothelial damage. The accumulation of thrombin then stimulates further angiogenesis and $A \beta$ production in a cycle of neurotoxic insult [47]. Other studies further support the interaction of $A \beta$ with thrombin and fibrin throughout the clotting cascade to increase neurovascular damage and neuroinflammation [52-54]. Expression of other pro-inflammatory cytokines, such as interleukin-1 $\beta$, is known to be increased [55] during AD. These cytokines can then induce VEGF expression [56], yielding the growth of new blood vessels. Cultured astrocytes stimulated with $\mathrm{A} \beta[57,58]$ release neuroinflammatory cytokines, resulting in the increased expression of VEGF. In mice, the reduction of $A \beta$-induced neuroinflammation [59] and angiogenesis [60] using the drug thalidomide has been documented.

There is substantial evidence implicating $A \beta$ as a modulator of blood vessel density and vascular remodeling through angiogenic mechanisms [61]. Moreover, the mechanism by which $A \beta$ stimulates angiogenesis is highly conserved and may be mediated through $\gamma$-secretase 
activity and Notch signaling. In vitro studies have demonstrated an angiogenic effect in human umbilical vein endothelial cells exposed directly to $A \beta 1-40$ and $A \beta 1-42$ [62]. Furthermore, the same cell line, when exposed to monomeric $A \beta$ or $\gamma$-secretase inhibitors, exhibited an increase in the number of tip cells and branches [63]. Other studies in post-mortem human brains also found evidence of increased angiogenesis in the hippocampus, midfrontal cortex, substantia nigra pars compacta, and locus ceruleus of AD brains compared with controls [24]. Further analysis found no correlation between the number of microglia and angiogenesis or microglia with vessel density, suggesting that it may be the presence of $A \beta$ that is initiating angiogenesis and subsequent vascular dysfunction.

The evidence for $\mathrm{A} \beta$-related angiogenesis has been extended in vivo. When the chick embryo chorioallantoic membrane assay was used, embryos stimulated with $A \beta 1-40$ and $A \beta 1-42$ had an increase in vascular growth [62]. Studies in zebrafish that express green fluorescent protein in vascular endothelial cells corroborated these results. Treatment with $\gamma$-secretase inhibitors or $A \beta$ resulted in significantly more vascular branching in the brain [63]. Studies in various APP mutant AD mouse models have also shown alterations in brain vasculature as a result of A $\beta$. APP23 mice exhibit significant blood flow alterations correlated with structural modifications of blood vessels [49]. Three-dimensional architectural analysis of young (3-month-old) and aged (up to 27-month-old) mice revealed significant alterations, particularly of the microvasculature. In young animals, small deposits were observed on microvessels, whereas in aged animals the vasculature appeared to abruptly end at amyloid plaques. Moreover, the brains of the aged mice exhibited a significant increase in $\beta$-3-integrin (a specific marker of activated endothelium) immunoreactivity, which was restricted to amyloidpositive vessels. Interestingly, brain homogenates from these mice resulted in the formation of new vessels in an in vivo angiogenesis assay that was blocked by a VEGF antagonist [56]. Overall, in both young and aged mice, the morphology of the vasculature appeared more dense and showed features typical of angiogenesis [64]. Although it should be noted that the vascular changes observed in these mice may be due to unrelated, 'off-target' effects of the APP mutation, this seems unlikely since the vascular changes observed in transgenic mice correlate well with vascular disturbances reported in human AD brains $[21,65]$.

In addition, the link between cerebral angiogenesis and hypoxia has been explored. Although cerebral hypoxic conditions are known to induce pro-angiogenic cytokines both in vitro [66] and in vivo [67], evidence of hypoxic angiogenesis is still unclear. For example, $A \beta$ has been shown to sequester VEGF [68], suggesting limited bioavailability of the cytokine. This study by Yang and colleagues [68] proposes that VEGF co-aggregates with $A \beta$ in
$\mathrm{AD}$ brains. The authors proposed that the very slow release of VEGF from the co-aggregated VEGF/A $\beta$ complex causes VEGF deficiency under the hypoxic conditions observed in $\mathrm{AD}$ brains. A related study attempted to examine the restorative effect of VEGF for AD in vivo [69] and found that intraperitoneal injection of VEGF in an $\mathrm{AD}$ mouse model ameliorated memory impairment in these mice compared with non-transgenic controls. Conflicting studies such as these on the role of proinflammatory cytokines in $\mathrm{AD}$ reflect the complexity of the etiopathology of AD. Although further work is needed to clarify the vascular response to conditions in the $\mathrm{AD}$ brain, these studies, taken together, show that disruptions to the neurovascular unit can influence cerebral ischemia, hypoxia, and neurodegeneration [70].

Finally, BBB dysfunction was initially identified in animal models of AD [21] and was later confirmed as a prominent, though unexplained, clinical feature of $\mathrm{AD}$ in patients [71]. Recently, we have demonstrated a significant increase in the incidence of disrupted tight junctions in aged Tg2576 AD model mice compared with controls and young animals. Moreover, we found that the pathology of the tight junction proteins occludin and ZO-1 was directly linked to an increased microvascular density but not apoptosis resulting from impaired CBF [65]. These data suggest that $A \beta$ itself is vasculotropic and support the notion that amyloidogenesis-triggered hypervascularity may be the basis for BBB disruption in AD (Figure 2) [65]. Our observations in patients with AD parallel those in the animal model of $A D$ in which we find a significant increase in cerebrovascular density compared with control patients. On the basis of these observations, we proposed a new hypothesis that is consistent with the literature relating to the $\mathrm{BBB}$ in $\mathrm{AD}$ : amyloidogenesis promotes extensive neoangiogenesis, leading to increased vascular permeability and subsequent hypervascularization in $\mathrm{AD}$ [65], which seeks to increase cerebrovascular flow. Although the direct involvement of $A \beta$ in influencing angiogenesis is controversial, recent direct evidence supports this hypothesis. Cameron and colleagues [63] demonstrated that $A \beta$ can directly influence angiogenesis via Notch signaling. The authors suggest that $A \beta$ acts as competitive inhibitor to de-repress signals for angiogenesis.

Immunotherapy continues to be explored as an experimental treatment option for AD. The unexpected negative vascular side effects seen in the early clinical trials of the human $\mathrm{AD}$ vaccine have prevented these therapies from reaching patients with AD; however, recent evidence suggests some optimism on this front [72]. We have recently examined whether immunization with $A \beta$ peptides can resolve amyloidogenesis-triggered angiogenesis and hypervascularity in the $\operatorname{Tg} 2576 \mathrm{AD}$ mouse. We find that a dramatic reversion of hypervascularization follows immunization with $A \beta$ [73]. This appears to be the first 


\section{A}

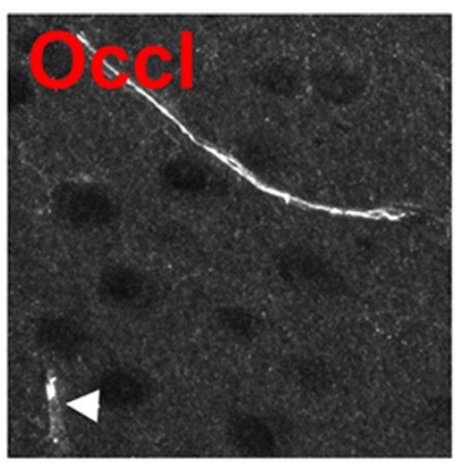

B
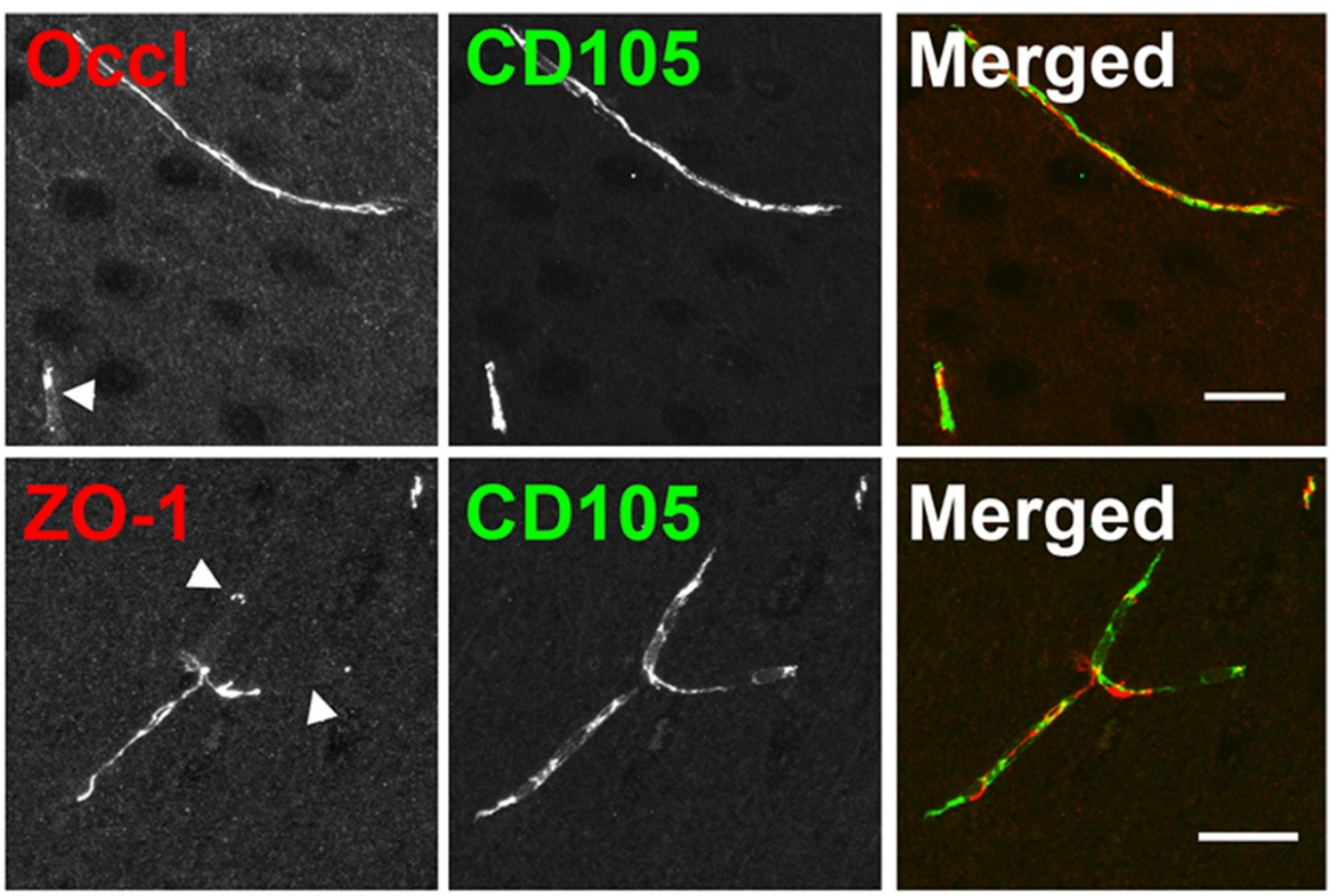

C
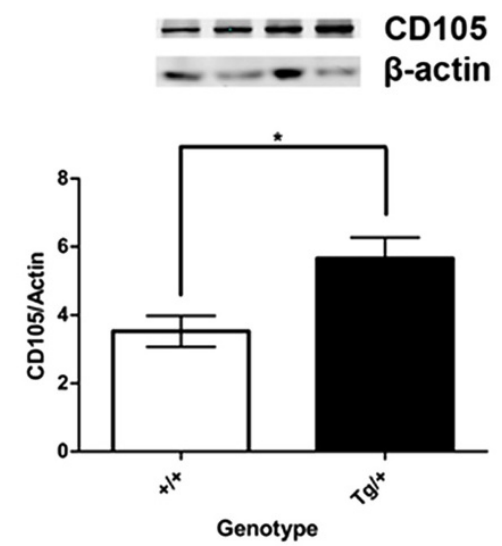

E

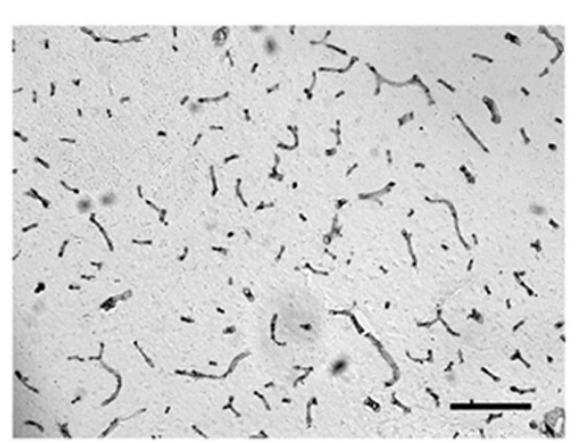

D

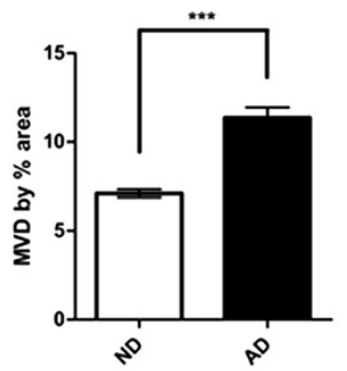

Patient classification

$\mathbf{F}$

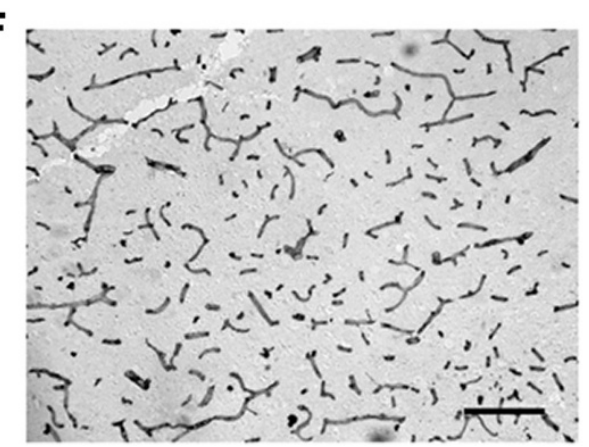

Figure $\mathbf{2}$ (See legend on next page.) 
(See figure on previous page.)

Figure 2 Angiogenesis, not apoptosis, induces alterations in blood-brain barrier (BBB) permeability in Alzheimer's disease (AD). Representative confocal micrographs of tight junctions (TJ). Hippocampal sections from aged wild-type and Tg2576 AD model mice are stained with either (A) Occludin (red) or (B) ZO-1 (red), and double-stained for CD105 (green), a known marker of angiogenesis. All vessels stained for CD105 regardless of the TJ expression pattern. Scale bar represents $20 \mu \mathrm{m}$. (C) Aged Tg2576 mice had significantly increased CD105 protein levels in the hippocampus compared with age-matched wild-type mice $\left(n=7,{ }^{*} P<0.05\right)$. (D) The hippocampus of the AD patient had a significantly increased microvascular density (MVD), as measured by percentage area occupied by laminin staining, compared with the ND (no disease) patient $\left(n=4,{ }^{* * *} P<0.001\right)$. Representative images of immunohistochemical staining for laminin in the cortex of the ND patient $(E)$ and the AD patient (F). Scale bar represents $95 \mu \mathrm{m}$. Values represent mean \pm standard error of the mean. Adapted from [65].

example of vascular reversion in which vascular density reverts to normal levels following therapeutic intervention. These findings clearly support a vascular angiogenesis model for AD pathophysiology and provide the first evidence that modulating angiogenesis repairs damage in the $\mathrm{AD}$ brain. In addition, we conducted a meta-analysis that quantified the endothelial (laminin) staining in the grey and white matter in the brain of a vaccinated patient with $\mathrm{AD}$, as originally described by Boche and colleagues [74]. Overall, immunized AD brains had an apparent reduced vascular density compared with relevant controls. In the grey matter, 390 brain endothelia were identified in the untreated patient with AD compared with 262 brain endothelia in the immunized patient with AD (a 33\% reduction after immunization). Similarly, in the white matter, 536 brain endothelia were identified in the untreated patient with $\mathrm{AD}$ compared with 402 brain endothelia in the immunized patient with $\mathrm{AD}$ (a 25\% reduction after immunization). Clearly, this is a small data set but should direct research toward expanding these analyses. It would also be interesting, as an extension of this study, to determine whether this treatment regime could clear both parenchymal and vascular $A \beta$ deposits. Overall, these data are consistent with the hypothesis that BBB leakiness in $\mathrm{AD}$ is due to $\mathrm{A} \beta$-triggered angiogenesis resulting in hypervascularity and that neutralizing this signal by immunization with $A \beta$ peptides removes the signal for angiogenesis. These data provide a strong link between brain vascularity and AD. However, in contrast to our recent findings, the over-inducement of angiogenesis was shown to reverse memory impairment and reduce ADlike neuropathologies in an AD mouse model [69]. Although this experiment cannot be directly compared with ours, it does support our idea that the key to $\mathrm{AD}$ pathogenesis is in the neurovasculature.

It has been reported that the murine PirB (paired immunoglobulin-like receptor B) and its human ortholog LilrB2 (leukocyte immunoglobulin-like receptor B2), present in human brain, are receptors for $A \beta$ oligomers, with nanomolar affinity leading to enhanced cofilin signaling. PirB contributes to memory deficits present in adult mice and mediates loss of synaptic plasticity in juvenile visual cortex. These findings imply that LilrB2 contributes to human AD neuropathology [75]; however,
PirB is an alternate receptor for Nogo-B, a neurite outgrowth inhibitor, and mediates vascular protection and facilitates vascular remodeling mediated by monocytes and macrophages. Therefore, PirB may play a more general role in regulating macrophage responses to vascular injury and subsequent angiogenesis [76].

Recently, the anti-proliferative drug bexarotene (Targretin; Medicis, a division of Valeant, West Laval, Quebec, Canada), a retinoid-X-receptor (RXR) agonist and previously approved as an oral anti-cancer agent, was shown to reduce $A \beta$ plaque burden and increase memory performance in an animal model of $\mathrm{AD}$ [77]. This study by

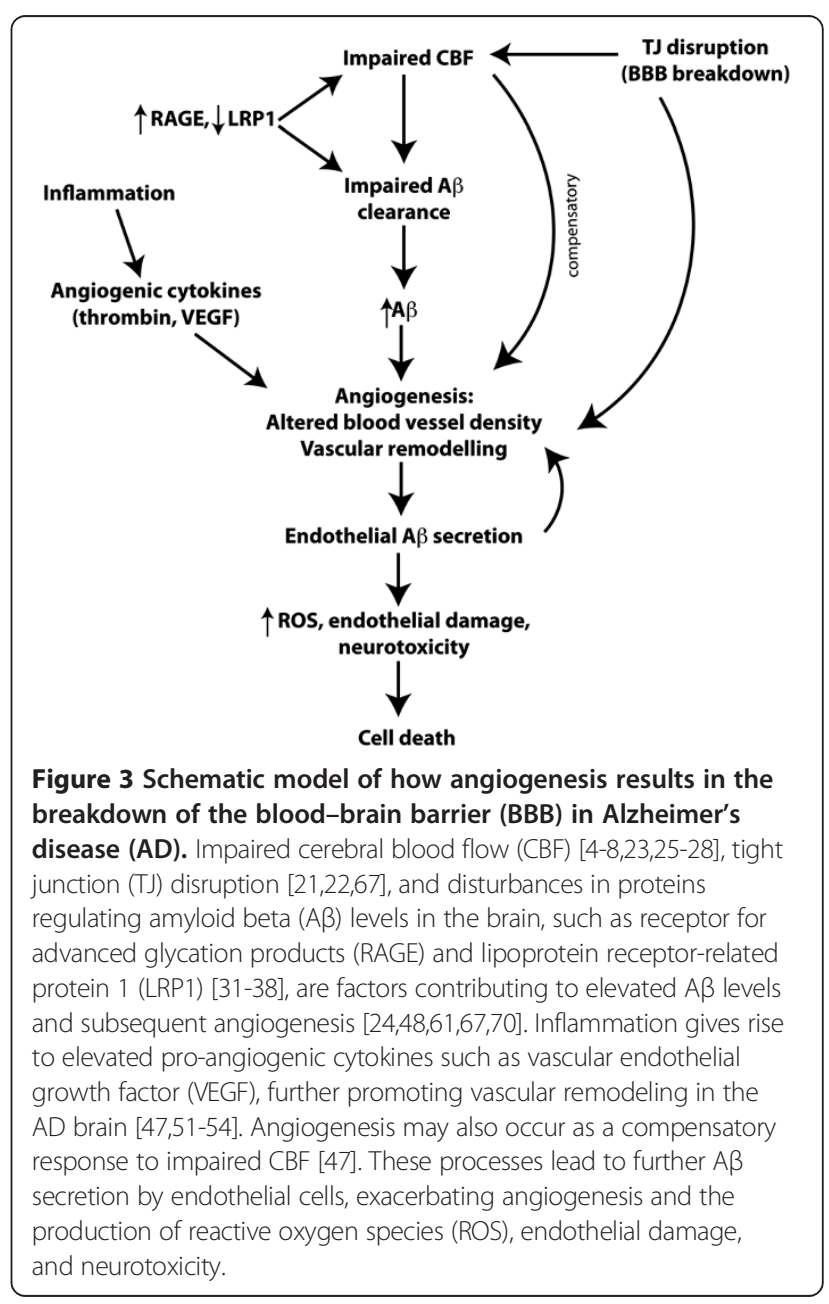


Cramer and colleagues [77] interprets bexarotene acting on RXRs to upregulate transcription of ApoE, a protein that is implicated in $A \beta$ plaque degradation. The improvement in hippocampal function is ultimately attributed by the reduction of plaque accumulation or turnover; nevertheless, other modes of action in AD are possible. These data are highly controversial; however, several reputable labs have reported that they have been unable to reproduce the key findings regarding the reduction in plaque burden and memory improvement in mice [78,79]. Interestingly, one of these studies did report a reduction in soluble $A \beta$ species [78], whereas another study observed behavioral improvement [80]. Nonetheless, other studies support bexarotene as a potential therapy for AD; for example, Fitz and colleagues [81] recently reported cognitive rescue and a reduction in A11-positive $\mathrm{A} \beta$ oligomers, and this was generally consistent with the findings from Cramer and colleagues [77]. The controversy surrounding the original article reflects the need for data to be reproduced by multiple labs before potential therapies such as bexarotene gain momentum as a panacea for AD. The response to the initial study reflects the desperation with which clinicians and patients are seeking an effective treatment for the disease. For this reason, bexarotene will undoubtedly continue to be assessed for its potential attenuation of $\mathrm{AD}$ pathology and effectiveness in $\mathrm{AD}$ therapy; however, other mechanisms of action for bexarotene may be found to be relevant for AD therapy. For example, bexarotene has been shown to directly exhibit an antiangiogenic effect by downregulating pro-angiogenic factors, such as VEGF, by acting through the activation of peroxisome proliferator-activated receptors [82]. Therefore, despite the controversy regarding bexarotene, studies that examine medications that have been approved by the US Food and Drug Administration for treatment of other diseases such as cancer may direct research toward reversing cerebrovasculature angiogenesis and provide a new and unexpected therapeutic modality for AD.

\section{Conclusions}

Many working models have been proposed to explain, in entirety, the pathophysiology of $\mathrm{AD}$, from the tau and amyloid hypotheses to the inflammation and lipodemic hypotheses. None of these models fully explains or fully incorporates all of the various aspects of the disease. It may be easier to fit these models by acknowledging that $\mathrm{AD}$ appears to be a syndrome rather than a single disease, and segmentation of this syndrome into various subcategories based on pathology or genetics may eventually provide explanations for each subcategory. This would also necessitate a reconsideration of the disparate disease features that have long confounded a unified chronopathological model of the disease. We had initially provided evidence of $\mathrm{BBB}$ leakiness and dysfunction in $\mathrm{AD}$ and this was expanded as the vascular model of AD. This BBB leakiness was first attributed to vascular dysfunction and deterioration but now appears to be clearly related to pro-angiogenic activity of amyloid itself. These new observations have allowed us to evolve the vascular model to incorporate our observations that hypervascularity appears in $\mathrm{AD}$ as a feature of the disease in human and animal brain (Figure 3). The question remains whether these observations can provide an explanation of $\mathrm{AD}$ as a syndrome or whether these observations apply to only a subcategory of the disease. It is certainly true that some patients with $\mathrm{AD}$ have no amyloid angiopathy at autopsy, whereas in others there is massive angiopathy and overall plaque burden. Similar discrepancies are seen with other biochemical features such as tau burden, but the clinical deterioration of these patients is very similar. Ultimately, for AD to be successfully treated, it may be necessary for us to consider that no single pharmacological intervention will effectively target all of the different causes at play. This can be likened to the treatment of cancer, in which the myriad causes and types may require different approaches to treatment for each patient. Although the use of anti-angiogenics in treating $\mathrm{AD}$ has demonstrated significant promise in experimental scenarios as we have described in this review, further work will be important for establishing the universal utility of anti-angiogenics for effective AD therapy.

\section{Abbreviations}

AD: Alzheimer's disease; ApoE: Apolipoprotein E; APP: Amyloid precursor protein; AB: Amyloid beta; BBB: Blood-brain barrier; CAA: Cerebrovascular amyloid angiopathy; CBF: Cerebral blood flow; LilrB2: Leukocyte

immunoglobulin-like receptor B2; LRP1: Lipoprotein receptor-related protein 1; PirB: Paired immunoglobulin-like receptor B; RAGE: Receptor for advanced glycation products; RXR: Retinoid-X-receptor; VEGF: Vascular endothelial growth factor.

\section{Competing interests}

The authors declare that they have no competing interests.

\section{Acknowledgments}

The authors thank all of the members of the WAJ and DLD laboratories for their participation in these studies. This work was supported by grants to WAJ from the Canadian Institutes of Health Research.

\section{Author details}

${ }^{1}$ Michael Smith Laboratories, The University of British Columbia, 301-2185 East Mall, Vancouver, BC V6T 1Z4, Canada. ²Department of Microbiology and Immunology, University of British Columbia, 1365-2350 Health Sciences Mall, Vancouver, BC V6T 1Z3, Canada. ${ }^{3}$ The Brain Research Centre, University of British Columbia, 2211 Wesbrook Mall, Vancouver, BC V6T 2B5, Canada. ${ }^{4}$ Centre for Blood Research, University of British Columbia, 2350 Health Sciences Mall, Vancouver, BC V6T 1Z3, Canada. ${ }^{5}$ Department of Zoology, University of British Columbia, 2370-6270 University Blvd, Vancouver, BC V6T 1Z4, Canada. ${ }^{6}$ Department of Medical Genetics, 1364-2350 Health Sciences Mall, Vancouver, BC V6T 1Z3, Canada. 'FFishberg Department of Neuroscience, Icahn School of Medicine at Mount Sinai, New York, NY 10029, USA.

${ }^{8}$ Friedman Brain Institute, Icahn School of Medicine at Mount Sinai, New York, NY 10029, USA. 


\section{References}

1. Hardy J, Selkoe DJ: The amyloid hypothesis of Alzheimer's disease: progress and problems on the road to therapeutics. Science 2002, 297:353-356.

2. Kalaria RN: Small vessel disease and Alzheimer's dementia: pathological considerations. Cerebrovasc Dis 2002, 13:48-52.

3. Dickstein DL, Walsh J, Brautigam H, Stockton SD Jr, Gandy S, Hof PR: Role of vascular risk factors and vascular dysfunction in Alzheimer's disease. Mt Sinai J Med 2010, 77:82-102.

4. Bookheimer SY, Strojwas MH, Cohen MS, Saunders AM, Pericak-Vance MA, Mazziotta JC, Small GW: Patterns of brain activation in people at risk for Alzheimer's disease. N Engl J Med 2000, 343:450-456.

5. ladecola C: Neurovascular regulation in the normal brain and in Alzheimer's disease. Nat Rev Neurosci 2004, 5:347-360.

6. Ruitenberg A, den Heijer T, Bakker SL, van Swieten JC, Koudstaal PJ, Hofman A, Breteler MM: Cerebral hypoperfusion and clinical onset of dementia: the Rotterdam Study. Ann Neurol 2005, 57:789-794.

7. Knopman DS, Roberts R: Vascular risk factors: imaging and neuropathologic correlates. J Alzheimers Dis 2010, 20:699-709.

8. Sheline YI, Morris JC, Snyder AZ, Price JL, Yan Z, D'Angelo G, Liu C, Dixit S, Benzinger T, Fagan A, Goate A, Mintun MA: APOE4 allele disrupts resting state $\mathrm{fMRI}$ connectivity in the absence of amyloid plaques or decreased CSF Abeta42. J Neurosci 2010, 30:17035-17040.

9. Kobayashi S, Tateno M, Utsumi K, Takahashi A, Saitoh M, Morii H, Fujii K, Teraoka M: Quantitative analysis of brain perfusion SPECT in Alzheimer's disease using a fully automated regional cerebral blood flow quantification software, 3DSRT. J Neurol Sci 2008, 264:27-33.

10. Matsuda H, Kitayama N, Ohnishi T, Asada T, Nakano S, Sakamoto S, Imabayashi E, Katoh A: Longitudinal evaluation of both morphologic and functional changes in the same individuals with Alzheimer's disease. J Nucl Med 2002, 43:304-311.

11. Bell RD, Zlokovic BV: Neurovascular mechanisms and blood-brain barrier disorder in Alzheimer's disease. Acta Neuropathol 2009, 118:103-113.

12. Glenner GG, Wong CW: Alzheimer's disease: initial report of the purification and characterization of a novel cerebrovascular amyloid protein. Biochem Biophys Res Commun 1984, 120:885-890.

13. Masters CL, Simms G, Weinman NA, Multhaup G, McDonald BL, Beyreuther $\mathrm{K}$ : Amyloid plaque core protein in Alzheimer disease and Down syndrome. Proc Natl Acad Sci U S A 1985, 82:4245-4249.

14. Johnston $H$, Boutin $H$, Allan SM: Assessing the contribution of inflammation in models of Alzheimer's disease. Biochem Soc Trans 2011, 39:886-890.

15. Banks WA: Drug delivery to the brain in Alzheimer's disease: consideration of the blood-brain barrier. Adv Drug Deliv Rev 2012, 64:629-639.

16. Selkoe DJ: Biochemistry and molecular biology of amyloid beta-protein and the mechanism of Alzheimer's disease. Handb Clin Neurol 2008, 89:245-260.

17. Alvarez G, Muñoz-Montaño JR, Satrústegui J, Avila J, Bogónez E, Díaz-Nido J: Regulation of tau phosphorylation and protection against beta-amyloidinduced neurodegeneration by lithium. Possible implications for Alzheimer's disease. Bipolar Disord 2002, 4:153-165.

18. Selkoe DJ: The cell biology of beta-amyloid precursor protein and presenilin in Alzheimer's disease. Trends Cell Biol 1998, 8:447-453.

19. Selkoe DJ: Translating cell biology into therapeutic advances in Alzheimer's disease. Nature 1999, 399:A23-A31.

20. Selkoe DJ: Toward a comprehensive theory for Alzheimer's disease. Hypothesis: Alzheimer's disease is caused by the cerebral accumulation and cytotoxicity of amyloid beta-protein. Ann N Y Acad Sci 2000, 924:17-25.

21. Ujiie M, Dickstein DL, Carlow DA, Jefferies WA: Blood-brain barrier permeability precedes senile plaque formation in an Alzheimer disease model. Microcirculation 2003, 10:463-470.

22. Dickstein DL, Biron KE, Ujiie M, Pfeifer CG, Jeffries AR, Jefferies WA: A\{beta\} peptide immunization restores blood-brain barrier integrity in Alzheimer disease. FASEB J 2006, 20:426-433.

23. Zlokovic BV: Neurovascular pathways to neurodegeneration in Alzheimer's disease and other disorders. Nat Rev Neurosci 2011, 12:723-738.

24. Desai BS, Schneider JA, Li JL, Carvey PM, Hendey B: Evidence of angiogenic vessels in Alzheimer's disease. J Neural Transm 2009, 116:587-597.

25. Bertram L, McQueen MB, Mullin K, Blacker D, Tanzi RE: Systematic meta-analyses of Alzheimer disease genetic association studies: the AlzGene database. Nat Genet 2007, 39:17-23.
26. Kim J, Basak JM, Holtzman DM: The role of apolipoprotein E in Alzheimer's disease. Neuron 2009, 63:287-303.

27. Verghese PB, Castellano JM, Holtzman DM: Apolipoprotein E in Alzheimer's disease and other neurological disorders. Lancet Neurol 2011, 10:241-252.

28. Thambisetty M, Beason-Held L, An Y, Kraut MA, Resnick SM: APOE epsilon4 genotype and longitudinal changes in cerebral blood flow in normal aging. Arch Neurol 2010, 67:93-98.

29. Zlokovic BV: The blood-brain barrier in health and chronic neurodegenerative disorders. Neuron 2008, 57:178-201.

30. Bell RD, Winkler EA, Sagare AP, Singh I, LaRue B, Deane R, Zlokovic BV: Pericytes control key neurovascular functions and neuronal phenotype in the adult brain and during brain aging. Neuron 2010, 68:409-427.

31. Yan SD, Chen X, Fu J, Chen M, Zhu H, Roher A, Slattery T, Zhao L, Nagashima M, Morser J, Migheli A, Nawroth P, Stern D, Schmidt AM: RAGE and amyloid-beta peptide neurotoxicity in Alzheimer's disease. Nature 1996, 382:685-691.

32. Mackic JB, Weiss MH, Miao W, Kirkman E, Ghiso J, Calero M, Bading J, Frangione B, Zlokovic BV: Cerebrovascular accumulation and increased blood-brain barrier permeability to circulating Alzheimer's amyloid beta peptide in aged squirrel monkey with cerebral amyloid angiopathy. J Neurochem 1998, 70:210-215.

33. Stern D, Yan SD, Yan SF, Schmidt AM: Receptor for advanced glycation endproducts: a multiligand receptor magnifying cell stress in diverse pathologic settings. Adv Drug Deliv Rev 2002, 54:1615-1625.

34. Deane R, Du Yan S, Submamaryan RK, LaRue B, Jovanovic S, Hogg E, Welch D, Manness L, Lin C, Yu J, Zhu H, Ghiso J, Frangione B, Stern A, Schmidt AM, Armstrong DL, Arnold B, Liliensiek B, Nawroth P, Hofman F, Kindy M, Stern D, Zlokovic B: RAGE mediates amyloid-beta peptide transport across the blood-brain barrier and accumulation in brain. Nat Med 2003, 9:907-913

35. Deane R, Zlokovic BV: Role of the blood-brain barrier in the pathogenesis of Alzheimer's disease. Curr Alzheimer Res 2007, 4:191-197.

36. Kang J, Lemaire HG, Unterbeck A, Salbaum JM, Masters CL, Grzeschik KH, Multhaup G, Beyreuther K, Müller-Hill B: The precursor of Alzheimer's disease amyloid A4 protein resembles a cell-surface receptor. Nature 1987, 325:733-736.

37. Hendriks L, van Duijn CM, Cras P, Cruts M, Van Hul W, van Harskamp F, Warren A, McInnis MG, Antonarakis SE, Martin J-J, Hofman A, Van Broeckhoven C: Presenile dementia and cerebral haemorrhage linked to a mutation at codon 692 of the beta-amyloid precursor protein gene. Nat Genet 1992, 1:218-221.

38. Deane R, Sagare A, Hamm K, Parisi M, Lane S, Finn MB, Holtzman DM, Zlokovic BV: apoE isoform-specific disruption of amyloid beta peptide clearance from mouse brain. J Clin Invest 2008, 118:4002-4013.

39. Miyazaki K, Ohta Y, Nagai M, Morimoto N, Kurata T, Takehisa Y, Ikeda Y, Matsuura T, Abe K: Disruption of neurovascular unit prior to motor neuron degeneration in amyotrophic lateral sclerosis. J Neurosci Res 2011, 89:718-728.

40. O'Kane RL, Martínez-López I, DeJoseph MR, Viña JR, Hawkins RA: Na (+)-dependent glutamate transporters (EAAT1, EAAT2, and EAAT3) of the blood-brain barrier. A mechanism for glutamate removal. J Biol Chem 1999, 274:31891-31895.

41. EIAli A, Hermann DM: ATP-binding cassette transporters and their roles in protecting the brain. Neuroscientist 2011, 17:423-436.

42. Zlokovic BV: New therapeutic targets in the neurovascular pathway in Alzheimer's disease. Neurotherapeutics 2008, 5:409-414.

43. Vinters HV: Cerebral amyloid angiopathy. A critical review. Stroke 1987, 18:311-324.

44. Holton JL, Ghiso J, Lashley T, Rostagno A, Guerin CJ, Gibb G, Houlden H, Ayling H, Martinian L, Anderton BH, Wood NW, Vidal R, Plant G, Frangione B, Revesz T: Regional distribution of amyloid-Bri deposition and its association with neurofibrillary degeneration in familial British dementia. Am J Pathol 2001, 158:515-526.

45. Richard E, Carrano A, Hoozemans JJ, van Horssen J, van Haastert ES, Eurelings $L S$, de Vries HE, Thal DR, Eikelenboom P, van Gool WA, Rozemuller AJ: Characteristics of dyshoric capillary cerebral amyloid angiopathy. I Neuropathol Exp Neurol 2010, 69:1158-1167.

46. Jellinger KA: The enigma of vascular cognitive disorder and vascular dementia. Acta Neuropathol 2007, 113:349-388.

47. Vagnucci AH Jr, Li WW: Alzheimer's disease and angiogenesis. Lancet 2003, 361:605-608. 
48. Kara F, Dongen ES, Schliebs R, Buchem MA, Groot HJ, Alia A: Monitoring blood flow alterations in the Tg2576 mouse model of Alzheimer's disease by in vivo magnetic resonance angiography at 17.6 T. Neuroimage 2012, 60:958-966.

49. Beckmann N, Schuler A, Mueggler T, Meyer EP, Wiederhold KH, Staufenbiel M, Krucker T: Age-dependent cerebrovascular abnormalities and blood flow disturbances in APP23 mice modeling Alzheimer's disease. J Neurosci 2003, 23:8453-8459.

50. Thal DR, Capetillo-Zarate E, Larionov S, Staufenbiel M, Zurbruegg S, Beckmann N: Capillary cerebral amyloid angiopathy is associated with vessel occlusion and cerebral blood flow disturbances. Neurobiol Aging 2009, 30:1936-1948

51. Pfeifer LA, White LR, Ross GW, Petrovitch H, Launer L: Cerebral amyloid angiopathy and cognitive function: the HAAS autopsy study. Neurology 2002, 58:1629-1634

52. Cortes-Canteli M, Paul J, Norris EH, Bronstein R, Ahn HJ, Zamolodchikov D, Bhuvanendran S, Fenz KM, Strickland S: Fibrinogen and beta-amyloid association alters thrombosis and fibrinolysis: a possible contributing factor to Alzheimer's disease. Neuron 2010, 66:695-709.

53. Zamolodchikov D, Strickland S: Abeta delays fibrin clot lysis by altering fibrin structure and attenuating plasminogen binding to fibrin. Blood 2012, 119:3342-3351

54. Paul J, Strickland S, Melchor JP: Fibrin deposition accelerates neurovascular damage and neuroinflammation in mouse models of Alzheimer's disease. J Exp Med 2007, 204:1999-2008.

55. Pogue Al, Lukiw WJ: Angiogenic signaling in Alzheimer's disease. Neuroreport 2004, 15:1507-1510.

56. Schultheiss C, Blechert B, Gaertner FC, Drecoll E, Mueller J, Weber GF, Drzezga A, Essler M: In vivo characterization of endothelial cell activation in a transgenic mouse model of Alzheimer's disease. Angiogenesis 2006, 9:59-65.

57. Fioravanzo L, Venturini M, Di Liddo R, Marchi F, Grandi C, Parnigotto PP, Folin $\mathrm{M}$ : Involvement of rat hippocampal astrocytes in beta-amyloid-induced angiogenesis and neuroinflammation. Curr Alzheimer Res 2010, 7:591-601.

58. Chiarini A, Whitfield J, Bonafini C, Chakravarthy B, Armato U, Dal Prà I: Amyloidbeta(25-35), an amyloid-beta(1-42) surrogate, and proinflammatory cytokines stimulate VEGF-A secretion by cultured, early passage, normoxic adult human cerebral astrocytes. J Alzheimers Dis 2010, 21:915-926.

59. Alkam T, Nitta A, Mizoguchi H, Saito K, Seshima M, Itoh A, Yamada K Nabeshima T: Restraining tumor necrosis factor-alpha by thalidomide prevents the amyloid beta-induced impairment of recognition memory in mice. Behav Brain Res 2008, 189:100-106

60. Ryu JK, McLarnon JG: Thalidomide inhibition of perturbed vasculature and glial-derived tumor necrosis factor-alpha in an animal model of inflamed Alzheimer's disease brain. Neurobiol Dis 2008, 29:254-266.

61. Ethell DW: An amyloid-notch hypothesis for Alzheimer's disease. Neuroscientist 2010, 16:614-617.

62. Boscolo E, Folin M, Nico B, Grandi C, Mangieri D, Longo V, Scienza R, Zampieri P, Conconi MT, Parnigotto PP, Ribatti D: Beta amyloid angiogenic activity in vitro and in vivo. Int J Mol Med 2007, 19:581-587.

63. Cameron DJ, Galvin C, Alkam T, Sidhu H, Ellison J, Luna S, Ethell DW: Alzheimer's-related peptide amyloid-beta plays a conserved role in angiogenesis. PLoS One 2012, 7:e39598.

64. Meyer EP, Ulmann-Schuler A, Staufenbiel M, Krucker T: Altered morphology and $3 D$ architecture of brain vasculature in a mouse model for Alzheimer's disease. Proc Natl Acad Sci U S A 2008, 105:3587-3592.

65. Biron KE, Dickstein DL, Gopaul R, Jefferies WA: Amyloid triggers extensive cerebral angiogenesis causing blood brain barrier permeability and hypervascularity in Alzheimer's disease. PLoS One 2011, 6:e23789.

66. Luo J, Martinez J, Yin X, Sanchez A, Tripathy D, Grammas P: Hypoxia induces angiogenic factors in brain microvascular endothelial cells. Microvasc Res 2012, 83:138-145.

67. Grammas P, Tripathy D, Sanchez A, Yin X, Luo J: Brain microvasculature and hypoxia-related proteins in Alzheimer's disease. Int J Clin Exp Pathol 2011, 4:616-627.

68. Yang SP, Bae DG, Kang HJ, Gwag BJ, Gho YS, Chae CB: Co-accumulation of vascular endothelial growth factor with beta-amyloid in the brain of patients with Alzheimer's disease. Neurobiol Aging 2004, 25:283-290.

69. Wang $P$, Xie ZH, Guo YJ, Zhao CP, Jiang H, Song Y, Zhu ZY, Lai C, Xu SL, Bi $J Z$ : VEGF-induced angiogenesis ameliorates the memory impairment in APP transgenic mouse model of Alzheimer's disease. Biochem Biophys Res Commun 2011, 411:620-626.
70. ladecola C: The overlap between neurodegenerative and vascular factors in the pathogenesis of dementia. Acta Neuropathol 2010, 120:287-296.

71. Farrall AJ, Wardlaw JM: Blood-brain barrier: ageing and microvascular disease - systematic review and meta-analysis. Neurobiol Aging 2009, 30:337-352

72. Menéndez-González M, Pérez-Piñera $P$, Martínez-Rivera M, Muñiz AL, Vega JA: Immunotherapy for Alzheimer's disease: rational basis in ongoing clinical trials. Curr Pharm Des 2011, 17:508-520.

73. Biron KE, Dickstein DL, Gopaul R, Fenninger F, Jefferies WA: Cessation of neoangiogenesis in Alzheimer's disease follows amyloid-beta immunization. Sci Rep 2013, 3:1354.

74. Boche D, Zotova E, Weller RO, Love S, Neal JW, Pickering RM, Wilkinson D, Holmes C, Nicoll JA: Consequence of Abeta immunization on the vasculature of human Alzheimer's disease brain. Brain 2008, 131:3299-3310

75. Kim T, Vidal GS, Djurisic M, William CM, Birnbaum ME, Garcia KC, Hyman BT, Shatz $C$ J: Human LilrB2 is a $\beta$-amyloid receptor and its murine homolog PirB regulates synaptic plasticity in an Alzheimer's model. Science 2013, 341:1399-1404.

76. Kondo Y, Jadlowiec CC, Muto A, Yi T, Protack C, Collins MJ, Tellides G, Sessa WC, Dardik A: The Nogo-B-PirB axis controls macrophage-mediated vascular remodeling. PLOS One

77. Cramer PE, Cirrito JR, Wesson DW, Lee CY, Karlo JC, Zinn AE, Casali BT, Restivo JL, Goebel WD, James MJ, Brunden KR, Wilson DA, Landreth GE: ApoE-directed therapeutics rapidly clear beta-amyloid and reverse deficits in AD mouse models. Science 2012, 335:1503-1506.

78. Veeraraghavalu K, Zhang C, Miller S, Hefendehl JK, Rajapaksha TW, Ulrich J, Jucker M, Holtzman DM, Tanzi RE, Vassar R, Sisodia SS: Comment on "ApoE-directed therapeutics rapidly clear beta-amyloid and reverse deficits in AD mouse models". Science 2013, 340:924-f.

79. Price $A R, X u G$, Siemienski ZB, Smithson LA, Borchelt DR, Golde TE, Felsenstein KM: Comment on "ApoE-directed therapeutics rapidly clear beta-amyloid and reverse deficits in AD mouse models". Science 2013, 340:924-d.

80. Tesseur I, Lo AC, Roberfroid A, Dietvorst S, Van Broeck B, Borgers M, Gijsen H, Moechars D, Mercken M, Kemp J, D'Hooge R, De Strooper B: Comment on "ApoE-directed therapeutics rapidly clear beta-amyloid and reverse deficits in AD mouse models". Science 2013, 340:924-e.

81. Fitz NF, Cronican AA, Lefterov I, Koldamova R: Comment on "ApoE-directed therapeutics rapidly clear beta-amyloid and reverse deficits in $A D$ mouse models". Science 2013, 340:924-c.

82. Yen WC, Prudente RY, Corpuz MR, Negro-Vilar A, Lamph WW: A selective retinoid $X$ receptor agonist bexarotene (LGD1069, targretin) inhibits angiogenesis and metastasis in solid tumours. Br J Cancer 2006, 94:654-660.

10.1186/alzrt230

Cite this article as: Jefferies et al:: Adjusting the compass: new insights into the role of angiogenesis in Alzheimer's disease. Alzheimer's Research \& Therapy 2013, 5:64 